\title{
A simple fish-based approach to assess the ecological quality of freshwater reservoirs in Central Europe
}

\author{
Petr Blabolil ${ }^{1,2}$, Milan Ríha $^{1}$, Daniel Ricard ${ }^{1,3}$, Jiří Peterka ${ }^{1}$, Marie Prchalová1 ${ }^{1}$ Mojmír Vašek ${ }^{1}$, \\ Martin Čech $^{1}$, Jaroslava Frouzová ${ }^{1}$, Tomáš Jůza ${ }^{1}$, Milan Muška ${ }^{1}$, Michal Tušer ${ }^{1}$, Vladislav Draštík ${ }^{1}$, \\ Zuzana Sajdlová $^{1,2}$, Marek Šmejka1 ${ }^{1,2}$, Lukáš Vejř́k ${ }^{1,2}$, Josef Matěna ${ }^{1}$, David S. Boukal ${ }^{2}$, \\ David Ritterbusch ${ }^{4}$ and Jan Kubečka, ${ }^{1, *}$ \\ ${ }^{1}$ Biology Centre of the Czech Academy of Sciences, Institute of Hydrobiology, Na Sádkách 7, 37005 České Budějovice, \\ Czech Republic \\ ${ }^{2}$ University of South Bohemia, Faculty of Science, Branišovská 31, 37005 České Budějovice, Czech Republic \\ ${ }^{3}$ Fisheries and Oceans Canada, Gulf Fisheries Centre, 343 avenue de l'Université, C.P. 5030, Moncton, NB E1C 9B6, Canada \\ ${ }^{4}$ Institut für Binnenfischerei e.V., Im Königswald 2, 14469 Potsdam, Germany
}

\begin{abstract}
The assessment of ecological quality in freshwater ecosystems is a key issue in many countries, but conditions for the development of assessment methodologies are often country-specific. This study proposes a simple methodology for the assessment of the ecological potential of reservoirs based on fish communities using a dataset covering major environmental and pressure gradients in reservoirs in the Czech Republic. Fish data obtained by gillnet sampling were correlated with a proxy of eutrophication as a key indicator of anthropogenic pressure for selecting appropriate fish-based indicators, establishing scoring criteria and developing the index of ecological quality. Expert judgement was also used to select potential fish indicators. Nine indicators were selected for the final fish-based index, fulfilling the criteria required by the Water Framework Directive. Two steps were used to validate the fish-based index quantification of its inter annual stability and sensitivity analysis of individual indicators. Finally, the index was compared to a previously developed general index for Central and Western Europe. Our study demonstrates that a combination of expert judgement and strict validation methods can result in an informative assessment of the ecological conditions, which can help identify conservation and restoration priorities.
\end{abstract}

Keywords: Artificial lakes / eutrophication / fish indicators / gillnets / index sensitivity / Water Framework Directive

Résumé - L'évaluation de la qualité écologique dans les écosystèmes d'eau douce est une priorité dans plusieurs pays, mais les conditions dictant le développement des méthodes d'évaluation sont souvent spécifiques à chaque pays. La présente étude propose une méthodologie simple pour l'évaluation du potentiel écologique des réservoirs basée sur les communautés de poissons en utilisant une banque de données couvrant les principaux gradients environnementaux et de pression des réservoirs de la République Tchèque. Les données de poissons obtenues par échantillonnage au filet maillant furent corrélées avec un proxy de l'eutrophisation comme indicateur clé des pressions anthropogéniques pour sélectionner des indicateurs appropriés basés sur les poissons, établissant des critères de notation et permettant le développement de l'indice final de qualité écologique. Le jugement d'experts a aussi été utilisé pour identifier des indicateurs potentiels basés sur les poissons. Neuf indicateurs furent sélectionnés pour l'indice final basé sur les poissons, remplissant ainsi le critère requis par la Directive-Cadre sur 1'Eau. Deux étapes furent utilisées pour valider l'indicateur final basé sur les poissons quantification de sa variabilité interannuelle et analyse de sensibilité des indicateurs individuels. Finalement, nous avons comparé l'indice final à un autre indice biologique général préalablement développé pour l'Europe central et l'Europe de l'ouest. Notre étude démontre qu'une combinaison de jugement

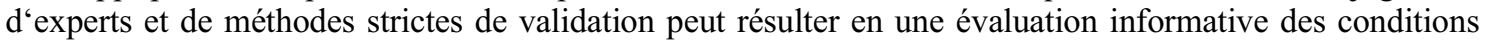
écologiques des réservoirs, permettant d'identifier les priorités de conservation et de restauration.

Mots-clés : Lac artificiel / eutrophisation / indicateur de poisson / filets maillants / directive cadre sur l'eau

\footnotetext{
*Corresponding author: kubecka@hbu.cas.cz
} 


\section{Introduction}

The human impact on water ecosystems is ubiquitous and usually leads to alterations of the environment (Karr et al., 1986; Scheffer et al., 2001). To mitigate negative human effects, substantial efforts are necessary to improve the ecological quality of degraded water bodies. The main European initiative for water quality assessment and improvements, the Water Framework Directive (WFD) (EC, 2000), requires all member states in the European community to assess the ecological quality of water bodies, often result in development of new assessment methodologies. The key assessment addresses ecological quality and involves the following four organismal groups: phytoplankton, aquatic flora, macroinvertebrates and fish. The quality of this assessment is highly dependent on the selection of relevant, sensitive indicators. Fish communities are among the best indicators of ecological quality in freshwaters because fish occupy all trophic levels, including top predators, in aquatic food webs, and therefore often integrate inputs and the effects of pressures across the ecosystem (Carpenter et al., 1985; Karr et al., 1986). Although each indicator has a limited explanatory power when used separately, their combination into a single index reflects an important part of the fish community and provides an adequate description of ecological conditions in water ecosystems (Karr et al., 1986). The long lifespan of many species also means that fish communities reflect changes over longer timescales. Therefore, many fish indices were developed to assess the ecological conditions in natural water ecosystems at national (Belpaire et al., 2000; Gassner et al., 2005; Søndergaard et al., 2005; Sutela et al., 2011; Kelly et al., 2012) and larger scales (Pont et al., 2007; Argillier et al., 2013).

WFD does not provide a binding protocol for the development of an assessment methodology. Due to differences in data availability and environmental gradients, different and partly incompatible approaches have been used to establish appropriate ecological quality indices in European Union member states (Birk et al., 2012). The amount of data and site-specific conditions greatly affect the analyses and wider applicability of the given ecological quality assessment. Within a small dataset, researchers can identify important drivers in each ecosystem and precisely evaluate its ecological quality (Gassner et al., 2003; Lammens et al., 2008). However, small datasets also have disadvantages. Their statistical analyses often lack power; thus, the assessment then requires expert judgement and empirical understanding (Gassner et al., 2003), which are prone to subjectivity and could reduce the credibility of the results in scientific and stakeholder communities. Small datasets also provide a limited scope for general conclusions. This contrasts with the potential of larger datasets covering more countries and larger environmental gradients to yield predictive models (Pont et al., 2007; Argillier et al., 2013) that may be difficult to apply in practice, because of lack of sensitivity to local particularities (Segurado et al., 2014).

The main emphasis in the ecological quality assessment for the WFD was, initially, on natural water bodies. Large datasets, spanning hundreds of European lakes and rivers, enabled the development of country-specific and panEuropean fish-based indices (Pont et al., 2007; Argillier et al., 2013), which were used to validate and harmonise national indices (Poikane et al., 2014). The WFD also requires an assessment of artificial water bodies, created by human activity, and heavily modified water bodies (HMWB) such as reservoirs, but the applicability of fish indices, developed for lakes, to reservoirs is questionable. Damming a river leads to a specific reservoir morphology and is dependent on the shape of the river valley prior to damming (Wetzel, 2001). Dam operation and human activities in the surrounding catchment also drive repeated disturbances and substantially change the character of reservoirs (Thornton et al., 1990; EC, 2000). This modification of a riverine ecosystem leads to transitional water bodies between natural lakes and rivers (Thornton et al., 1990; Wetzel, 2001), in which fish communities adapt (Irz et al., 2006).

Reservoirs are built to provide valuable socioeconomic benefits (e.g., water storage, flood defence, hydropower generation, and navigation). Many alterations, such as interference in fluvial processes, habitat fragmentation, the deterioration of surrounding irrigation, and a reduction of traditional fisheries, including the extinction of native and, especially, migratory species (McCluney et al., 2014, Agostinho et al., 2016), are inherent trade-offs with reservoir functions. However, following the WFD criteria many negative effects cannot be considered as pressures if they cannot be mitigated without compromising the primary reservoir functions or leading to other significant adverse effects on the ecosystem or human society. Ecological quality assessment of reservoirs should therefore quantify an ecological potential (EP) that considers the physical alteration by human activities linked with reservoir functions (EC, 2000). On the other hand, appropriate objectives can be set for the management of other pressures that are not associated with reservoir functioning and whose adverse ecological effects can be mitigated without undermining the socioeconomic benefits.

The first step in the improvement of the EP of reservoirs is the development of an assessment system to evaluate the current situation. Little interest in the ecological quality of reservoirs has led to limited comparable data on fish communities and non-standardized datasets from reservoirs across most European countries (Kubečka et al., 2009). This lack of interest has left a substantial gap in the understanding of the drivers of ecological quality across the full range of European freshwater ecosystems. Ongoing detailed research of riverine reservoirs in the Czech Republic provides an excellent opportunity to fill this gap and provide a methodology to assess their ecological quality to fulfil the WFD requirements. Reservoirs are the main type of large water bodies with stable fish communities in the country; more than 40 reservoirs larger than 50 hectares were created during the 20th century. However, they already suffer from eutrophication, the main pressure of aquatic ecosystems in the Czech Republic and elsewhere in Europe (Birk et al., 2012; Argillier et al., 2013), which causes substantial alterations to the reservoir ecosystems (Wetzel, 2001).

This study develops an easy to use fish-based index to assess the EP of Czech reservoirs (CZ-FBI), based on a dataset covering 17 reservoirs. The limited nature of the dataset necessitated the inclusion of expert judgement. To address the possible shortcomings previously outlined, the index was validated by a two-step procedure including quantification of inter annual stability and sensitivity analysis. Parallel to this 
endeavour, other datasets covering larger regions of Central and Western Europe became available, allowing for the development of an independent, general fish-based index for reservoirs using more robust statistical analyses to characterize the abundance (total abundance) and composition (two guild indicators) of the fish community (Blabolil et al., 2016, CWEFBI). Comparison of the two independent indices provides the possibility to discuss their applicability, strengths and weaknesses in the assessment of the EP in reservoirs.

\section{Materials and methods}

\subsection{Development of the CZ-FBI}

A total of 17 reservoirs located in the Czech Republic (Central Europe, ecoregion 9 and 11 by Illies, 1978) were sampled between 2004 and 2012, yielding a dataset of 41 reservoir-years, since many reservoirs were sampled repeatedly in different years. Only the latest survey per reservoir was used in the development of the CZ-FBI, but data from repeated surveys were compared to evaluate temporal stability (see below). All reservoirs have an average depth greater than $5 \mathrm{~m}$ and are thermally stratified during the summer months. They are located in different parts of the Czech Republic and cover large gradients of key environmental characteristics (e.g., a reservoir area of 17-4870 ha, a maximum depth of 12-74 m, an altitude of $276-737 \mathrm{~m}$ a s 1$)$ and pressures $(100 \%$ natural cover in up to $73 \%$ of agriculture land use in the catchment; a total phosphorus concentration between 7.9 and $62.6 \mu \mathrm{g} \cdot \mathrm{L}^{-1}$ ); see Table S1 for details.

\subsection{Sampling}

All reservoirs were sampled between July and September during periods of strong thermal and oxygen stratification using two type of gillnets. The total sampling effort was based on reservoir area and maximum depth, following the European sampling protocol (EN 14757 2005); see Table S2 for details. Due to a strong longitudinal gradient in environmental conditions, gillnets were deployed in selected localities a priori with similar trophic characteristics along the gradient (dam and tributary) using a stratified random sampling design. Herein, 'dam' refers to the locality closest to the outflow with lacustrine characteristics and 'tributary' denotes a locality closest to the inflowing river with riverine characteristics.

The benthic habitat, defined as a layer extending $1.5 \mathrm{~m}$ above the bottom, was sampled by benthic gillnets (BG) lying on the bottom. Depth layers for BG (i.e., local bottom depths) were set to $0-3,3.1-6,6.1-9,9.1-12,12.1-18$ and $>20 \mathrm{~m}$ if the maximum depth at that locality was $>20 \mathrm{~m}$ and were reduced with the same $3 \mathrm{~m}$ step in shallower localities. The pelagic habitat was sampled by three types of pelagic gillnets (PG) installed offshore, in open water above the original river valley with the highest depth, never overlapping with BG. Surface PG were set from the surface to $3 \mathrm{~m}$ deep. Meso-PG were set to the depths of 3-6 and 6-9 $\mathrm{m}$ and were equipped with floaters on 3 and $6 \mathrm{~m}$ long strings, respectively. Bathy-PG, with weights on $5 \mathrm{~m}$ strings attached to the lead line, were set to the depth layer that was 5-9 $\mathrm{m}$ above the bottom. All three PG types were used if the maximum local depth exceeded $20 \mathrm{~m}$; epi- and mesopelagic gillnets were applied at localities deeper than $10.5 \mathrm{~m}$, and epipelagic gillnets were used in the relatively shallow, uppermost sites with depths $>4.5 \mathrm{~m}$. Both BG and PG consisted of gillnets of 12 mesh sizes $(5,6.25,8,10,12.5,15.5$, $19.5,24,29,35,43$ and $55 \mathrm{~mm}$ ), following the CEN 14757 standard (CEN, 2005). PG includes extra $5 \mathrm{~mm}$ mesh size (contrary to CEN 14757 standard) and four large mesh sizes $(70,90,110$ and $135 \mathrm{~mm})$ were added to both type of gillnets to capture larger fish (Šmejkal et al., 2015). The total length of each net was $60 \mathrm{~m}(16 \times 2.5 \mathrm{~m}$ panels $)$. The height of the BG was $1.5 \mathrm{~m}$, and that of the PG was $3 \mathrm{~m}$ (epi- and mesopelagic) and $4.5 \mathrm{~m}$ (bathypelagic). At each locality and depth, three nets were deployed at a distance of $60 \mathrm{~m}$ and were handled separately as independent samples with all mesh sizes together. All gillnets were set before sunset and were lifted after sunrise to cover maximal peaks of fish activity (Prchalová et al., 2010).

All fish were identified by species and were measured to the nearest $1 \mathrm{~mm}$ for fish of standard length $<100 \mathrm{~mm}$ or in $5 \mathrm{~mm}$ intervals for larger fish. Individual weight (in grams) and age data (based on scales in Cyprinidae and Esocidae and on otoliths in Percidae, Salmonidae and Siluridae) were taken for all specimens or, in common species, for a random subsample of 50 fish per survey. Age and weight estimations in the remaining fish were based on length-frequency distribution and lengthweight relationships. The abundance and biomass of the catch were expressed as the number of individuals (abundance) and fish weight ( $\mathrm{kg}$, biomass) per unit of sampling effort $\left(1000 \mathrm{~m}^{2} \cdot\right.$ night $\left.^{-1}\right)$, hereafter, NPUE and BPUE, respectively.

\subsection{Development of assessment methodology}

A total of 48 characteristics representing different guilds and stocking regime was included among potential fish indicators that differed in their expected response to eutrophication (Tab. S3). The selection of indicators was based on a literature review (e.g., Schmidt-Kloiber and Hering, 2015; Blabolil et al., 2016; Froese and Pauly, 2016) and additional empirical knowledge in order to reflect the responses of fish communities to negative anthropogenic impacts. The indicators were selected to fulfil the WFD evaluation criteria of abundance, composition and age structure of fish assemblages (EC, 2000).

Because of the highly stochastic recruitment affecting young-of-the-year $(0+)$ fish (Jüza et al., 2014) and their underestimation by gillnet surveys (CEN, 2005, Prchalová et al., 2009), the indicators were evaluated only for fish older than $0+$. The only exceptions were indicators evaluating the age structure where all age classes were used.

Indicators describing the whole fish assemblage and related to the WFD evaluation criterion of abundance, i.e., total NPUE and BPUE, were included because fish abundance and biomass commonly increase with nutrient loading (e.g., Belpaire et al., 2000; Søndergaard et al., 2005; Launois et al., 2011a,b; Kelly et al., 2012; Argillier et al., 2013). These indicators were calculated separately for benthic and pelagic habitats (the latter at the depths of $0-6 \mathrm{~m}$, i.e., a combination of surface and mesopelagic gillnets) for dam, tributary, and the whole reservoir and as an average of both habitats across the entire reservoir. The distinction between dam and tributary was necessitated by the strong longitudinal environmental gradient in most of the reservoirs described above. 
Most of the composition indicators were single-species indicators related to the WFD criteria on community composition. Since species differ in their fundamental or realized niches (Hutchinson, 1957), the impact of different anthropogenic pressures should be mostly species-specific. Therefore, relative BPUE in benthic and pelagic habitats and as averages of both habitats of the most common and abundant species, i.e., common bream (Abramis brama), roach (Rutilus rutilus), rudd (Scardinius erythrophthalmus), pikeperch (Sander lucioperca), European perch (Perca fluviatilis), and common carp (Cyprinus carpio) were chosen as candidate indicators (Tab. S3). The only exception was ruffe, a smallbodied species (adult weight 50-100 g) associated exclusively with a benthic habitat, for which the numerical abundance in benthic habitats was used because it contributes little to total biomass, even at high population densities (Tab. S3).

One indicator covered the relative biomass of cold-water species from the family Salmonidae (brown trout Salmo trutta, rainbow trout Oncorhynchus mykiss, grayling Thymallus thymallus, maraena whitefish Coregonus maraena, and peled whitefish Coregonus peled) in a reservoir. These species share important ecological requirements, including a preference for cold and oxygen-rich waters (Gassner et al., 2003, 2005; Carol et al., 2006). They were found mainly at higher altitudes (see Tabs. S1 and S2) as their ability to live in thermally stratified reservoirs depends on high oxygen saturation of the hypolimnion, which is often reduced by eutrophication (Wetzel, 2001).

The relative biomass of phytophilous species was included as a candidate indicator of littoral degradation and main productivity in the pelagic habitat (Jeppesen et al., 2005). Well-developed littoral habitats can buffer bank erosion, sink nutrients controlling the algal and cyanobacterial production, provide spawning grounds and refuges for $0+$ fish, hunting grounds for ambush predators, and habitats for many other organisms such as macroinvertebrates (Krolová et al., 2013; Stefanidis and Papastergiadou, 2013). The guild of phytophilous fish included species whose reproductive success depends on the presence of submerged vegetation such as crucian carp (Carassius carassius), rudd and tench (Tinca tinca). Northern pike (Esox lucius) and common carp, another typical phytophilous species, were not included because they are the most commercially important species for angling in the country and the populations in reservoirs are primarily driven by stocking (CFU, 2017; Boukal et al., 2012).

The last WFD criterion, assessment of age structure, was determined indirectly by two types of indicators, the population size structure and the presence of recruits. The size structure of the most common species was characterized by the 75th percentiles of the respective length distribution. Recruitment was based on the presence of $0+$ individuals for the following six species: common bream, roach, bleak (Alburnus alburnus), ruffe, European perch and pikeperch because of wide distribution and different water quality demands. Reservoirs should not be considered as completely degraded when fish reproduction occurs, even under otherwise strong pressure (e.g., in hypereutrophic reservoirs with toxic algae blooms). We assumed that at least two of the six species should be able to reproduce to increase the ecological quality. We included only the presence/absence and not NPUE nor BPUE criteria for $0+$ fish. Presence data are more reliable than catch per unit effort for $0+$ fish as gillnets underestimated the quantity of small fish (Prchalová et al., 2009). The only exception to exclude this indicator are reservoirs dominated by European perch. High perch population have high predation pressure to $0+$ fish and it can strongly reduce quantity of $0+$ fish in a reservoir. The threshold of a reasonable limit for strong predator pressure was set a priori to $20 \%$ biomass of European perch in the total community (Kubečka, 1993).

\subsection{Selection of indicators}

Because of the limited dataset, a simple statistical method was chosen for selecting appropriate indicators. In the first step, the relationship between each indicator and total phosphorus (TP) concentration was evaluated, since total phosphorus is a good proxy for eutrophication (Vollenweider, 1976). TP for each reservoir was defined as a three-year average (year of sampling plus two previous years) from data collected in the epilimnetic layer during the vegetative season (April to September) at 2-6 localities along the longitudinal profile of each reservoir. Indicators showing substantial correlation with TP (Spearman correlation coefficient $\rho_{\mathrm{TP}}>$ 0.3 ) and supported by literature and expert opinions were chosen for analysis.

To avoid redundancy in the selected indicators, Spearman correlations between the different fish indicators within each type of WFD criteria (abundance, composition, and age structure of fish assemblages) were computed to identify highly correlated, redundant indicators $(\rho>0.8$; Argillier et al., 2013; Blabolil et al., 2016) and obtain a parsimonious set of indicators. If two indicators were highly correlated, the one with the tighter correlation with TP was retained. In addition, the relative biomass of Salmonidae and presence of $0+$ fish were considered ecologically important for reasons explained above and to fulfil WFD requirements.

None of the sampled reservoirs could be considered as fully undisturbed and used as a reference site for the others. Therefore, a gradient in TP concentration in the reservoirs ranging from the lowest (deemed as the least disturbed state) to the highest (most disturbed state) was used to score indicators correlating substantially with TP. For each of this indicator the best values (i.e., the lowest values for indicators positively correlated with TP and the highest for indicators correlated negatively with TP) were utilized as the dataset-specific reference values. The value range of each indicator was divided to obtain appropriate class boundaries. Prior to that, repeated zero values for species absence were collapsed to one zero value for each indicator, as multiple zeroes could highly affect quartile values in this dataset (Tab. S2). The first class boundary between good and moderate status was set to the first quartile of indicator range. The second boundary between moderate and poor status was set to twice and half the value of the first boundary, for indicators positively and negatively correlated with TP, respectively. Second class boundary for relative biomass of rudd, both class boundaries for relative biomass of Salmonidae and presence of $0+$ fish were set based on expert judgement. The status of each indicator was then scored as good, moderate or poor quality and given 5,3 or 1 standardize values of the indicator, respectively (Ritterbusch, 2011). 
Table 1. Fish indicators used in the CZ-FBI index. Gear = extent of source data (i.e., gear and depth strata); $\rho_{\mathrm{TP}}=$ correlation coefficient with total phosphorus; poor, moderate and good class (with standardize value of the indicator in parentheses) $=$ value ranges for each category of ecological class; WFD criteria = criterion type used for the assessment of ecological potential. NA: $\rho_{\text {TP }}$ was not calculated because of only two values in the dataset; gear: benthic (BG) or pelagic (PG) gillnets; all = data from all strata. All indicators except the last one are based on fish older than $0+$.

\begin{tabular}{|c|c|c|c|c|c|c|}
\hline Indicators & Gear & $\rho_{\mathrm{TP}}$ & $\begin{array}{l}\text { Poor class } \\
\text { (1) }\end{array}$ & $\begin{array}{l}\text { Moderate class } \\
\text { (3) }\end{array}$ & $\begin{array}{l}\text { Good class } \\
(5)\end{array}$ & WFD criteria \\
\hline 1. Total fish biomass in dam part $\left[\mathrm{kg} \cdot 1000 \mathrm{~m}^{-2}\right]$ & PG $0-6 \mathrm{~m}$ & 0.37 & $>35$ & $17-35$ & $<17$ & Abundance \\
\hline 2. Total fish biomass in tributary part $\left[\mathrm{kg} \cdot 1000 \mathrm{~m}^{-2}\right]$ & PG $0-6 \mathrm{~m}$ & 0.58 & $>70$ & $35-70$ & $<35$ & Abundance \\
\hline 3. Total fish abundance [ind $\left.\cdot 1000 \mathrm{~m}^{-2}\right]$ & BG all & 0.59 & $>600$ & $300-600$ & $<300$ & Abundance \\
\hline 4. Relative biomass of common bream [\%] & BG all & 0.55 & $>10$ & $5-10$ & $<5$ & $\begin{array}{l}\text { Community } \\
\text { composition }\end{array}$ \\
\hline 5. Relative abundance of ruffe $[\%]$ & BG all & 0.53 & $>20$ & $10-20$ & $<10$ & $\begin{array}{l}\text { Community } \\
\text { composition }\end{array}$ \\
\hline 6. Relative biomass of European perch [\%] & PG all & -0.57 & $<10$ & $10-20$ & $>20$ & $\begin{array}{l}\text { Community } \\
\text { composition }\end{array}$ \\
\hline 7. Relative biomass of rudd [\%] & BG and PG all & -0.62 & $<1$ & $1-5$ & $>5$ & $\begin{array}{l}\text { Community } \\
\text { composition }\end{array}$ \\
\hline 8a. Relative biomass of Salmonidae $[\%]<700 \mathrm{~m}$ a s 1 . & BG and PG all & -0.12 & $<1$ & $1-2$ & $>2$ & $\begin{array}{l}\text { Community } \\
\text { composition }\end{array}$ \\
\hline 8b. Relative biomass of Salmonidae $\geq 700 \mathrm{~m}$ a s 1 . & BG and PG all & NA & $<2$ & $2-5$ & $>5$ & $\begin{array}{l}\text { Community } \\
\text { composition }\end{array}$ \\
\hline $\begin{array}{l}\text { 9. Presence of } 0+\text { fish of } 6 \text { species (common bream, roach, } \\
\text { bleak, ruffe, European perch, pikeperch) }\end{array}$ & BG and PG all & 0.59 & $<2$ & $2-3$ & $>3$ & Age structure \\
\hline
\end{tabular}

After evaluating all selected indicators in each reservoir, the ecological quality ratio (EQR) was computed as $\mathrm{EQR}=\left(S-S_{\min }\right) /\left(S_{\max }-S_{\min }\right)$, where $S$ is the sum of standardize values of the indicator for all fish indicators assessed in a reservoir, $S_{\min }$ is the number of indicators (each indicator has a minimum value of one standardize value of the indicator) and $S_{\max }$ is five times the number of indicators (each indicator has a maximum value of five standardize values of the indicator). The resulting EQR values range between 0 and 1,0 being the most degraded and 1 being the least degraded.

Finally, class boundaries for total EQR were set at 25\% intervals that yielded four baseline classes of EP; the upper quartile was further split into two parts, such that the theoretical reference status was set to the upper 0.1 of the total range. This setting was done because of observed biological changes in fish communities and WFD requirements to set four classes, but the class 'Good and above' refer to the Good and equivalent to High class in ecological status of natural water bodies (EC, 2000). The final classification of EQR therefore was as follows: High $(1 \leq \mathrm{EQR} \geq 0.9)$, Good $(0.9<\mathrm{EQR} \geq$ $0.75)$, Moderate $(0.75<\mathrm{EQR} \geq 0.5)$, Poor $(0.5<\mathrm{EQR} \geq$ $0.25)$, and $\mathrm{Bad}(0.25<\mathrm{EQR} \geq 0)$. This procedure resulted in the Czech fish-based index (CZ-FBI) of classifying reservoirs based on their EP. Because of its relative simplicity, a subsequent validation procedure was necessary.

\subsection{Validation procedure}

Validation consisted of two independent steps. First, longterm stability of the CZ-FBI was evaluated for seven reservoirs with data from multiple surveys. Temporal stability is a necessary prerequisite for a biologically meaningful index in constant conditions: the classification of EP should not change dramatically (i.e., fall in two different classes) within a few years if no relevant management measures were implemented.

Second, the whole dataset of 41 reservoir-years was used to examine which indicators have the strongest effect on EQR values with a sensitivity test. This is important as many types of the underlying data cannot be measured without error and/or their assessment is necessarily subjective. Each indicator value was perturbed by $\pm 10 \%$ and $\pm 25 \%$ and scored; the EQR was then calculated. The percentage of cases when the EQR value changed between ecological classes was evaluated for each indicator.

\subsection{Comparison of CZ-FBI to the previously developed CWE-FBI}

A general assessment methodology was previously developed for reservoirs in Central and West Europe (CWEFBI, see Blabolil et al., 2016 for details), encompassing the same dataset used here, plus three additional Czech reservoirs and 124 French reservoirs. Only data collected by the standard 12 mesh size benthic gillnets without the addition of larger mesh nets were used. The statistical approach was different (hindcast modelling, Baker et al., 2005), using basic environmental variables (temperature, reservoir and catchment area, maximum depth and theoretical retention time) and two proxies of eutrophication (TP concentration and percentage of agricultural land use in the reservoir catchment) to control for environmental and pressure variability.

The four indicators used in the CWE-FBI are functional, rather than taxonomical, and include total BPUE and NPUE of 


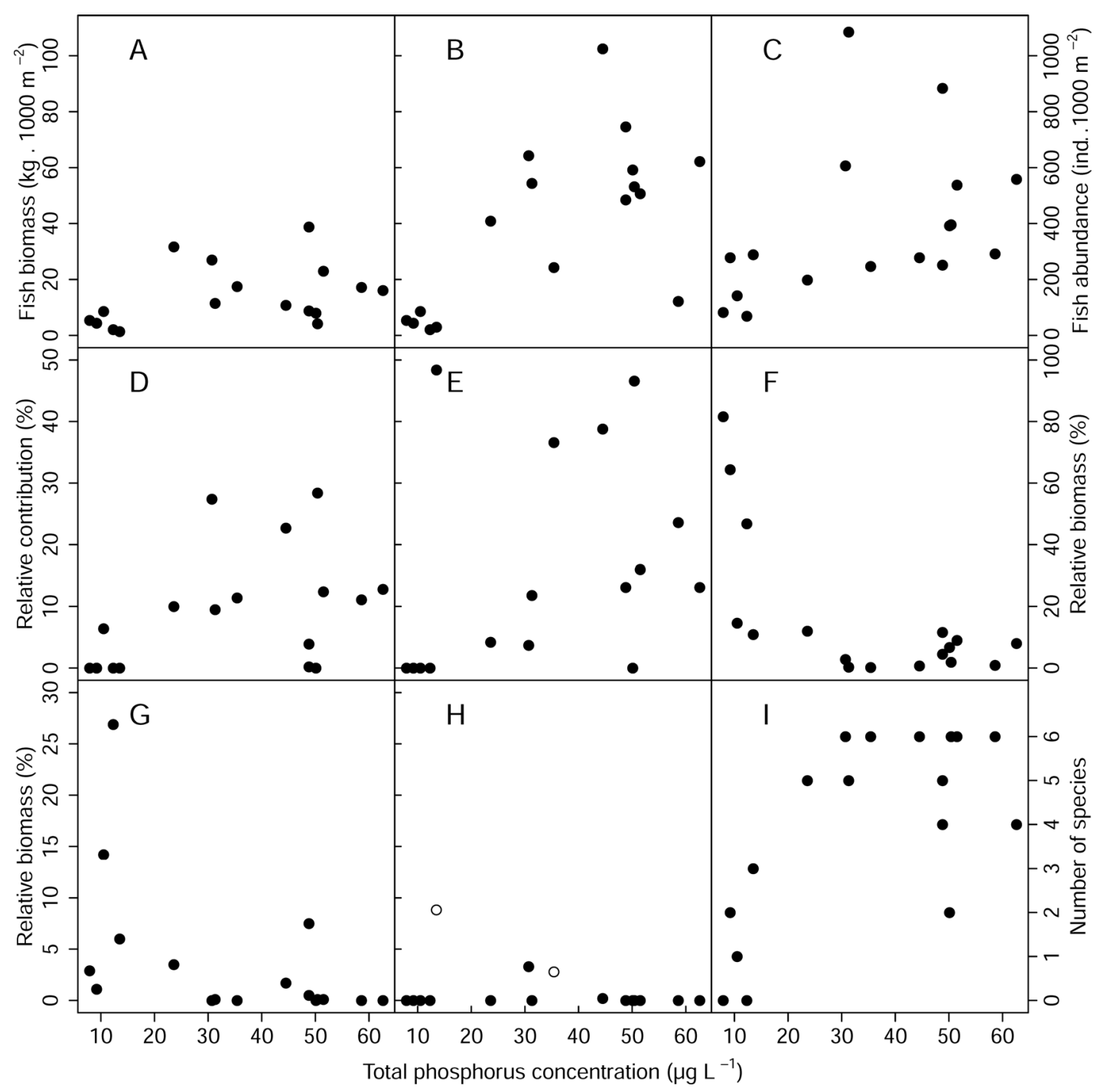

Fig. 1. Relationships between fish indicators and total phosphorus concentration. First two columns share $y$-axis. A=total fish biomass in dam part, $\mathrm{B}=$ total fish biomass in tributary part, $\mathrm{C}=$ total fish abundance, $\mathrm{D}=$ relative biomass of common bream, $\mathrm{E}=$ relative abundance of ruffe, $\mathrm{F}=$ relative biomass of European perch, $\mathrm{G}=$ relative biomass of rudd, $\mathrm{H}=$ relative biomass of Salmonidae (black circles reservoirs $<700 \mathrm{~m}$ a $\mathrm{s} 1$ and empty circles $\geq 700 \mathrm{~m}$ a s 1 ), $\mathrm{I}=$ presence of $0+$ fish of six species.

invertivorous/piscivorous fish (mainly European perch and pikeperch) and the NPUE of planktivorous fish (mainly common bream and bleak), always integrating the whole benthic habitat. This ensures that both indices do not include the same set of indicators, which alone could lead to highly correlated EQR values between the two indices. The EQR scale was the same in CWE-FBI as in CZ-FBI: a value of 1 means a healthy/reference ecosystem and a value of 0 means a degraded ecosystem (Blabolil et al., 2016), enabling direct comparison by linear regression of both classification methodologies in parallel datasets. All analyses were performed using $\mathrm{R}$ software ( $\mathrm{R}$ version 3.0.1, R Core Team, 2015).

\section{Results}

Data from the 17 Czech reservoirs provided enough contrast to justify meaningful analyses (Tab. S2). The total catch, expressed as total BPUE and NPUE, was highly variable (minimum-maximum BPUE and NPUE: $1-72 \mathrm{~kg}$ and 69-1085 ind $\cdot$ per $1000 \mathrm{~m}^{2}$, respectively). In total, 32 fish species were captured (4-17 per reservoir). The most widespread species was European perch, which was found in all reservoirs. Other widespread species were roach and rudd, which were caught in 15 reservoirs. Asp (Leuciscus aspius), common bream, common carp, wels catfish (Silurus glanis), northern pike, pikeperch and ruffe were observed in more than 10 reservoirs.

\subsection{Selection of indicators and development of the fish index}

Nine fish indicators from the total of the 48 tested were selected for the calculation of EQR (Tab. 1). Seven indicators correlated tightly $(\rho<-0.4$ or $\rho>0.4)$ with TP and covered a sufficiently wide range to allow the delimitation of scoring classes (Fig. 1). These indicators were complemented with relative biomass of Salmonidae and presence of $0+$ fish (see above). 
Three selected indicators fulfilled the WFD criterion of abundance evaluation (Tab. 1). Both the total abundance and biomass of fish increased with nutrient concentration. Better fit for fish biomass was observed in pelagic than in benthic habitats $(\rho=0.37$ vs. 0.33 in dam and 0.58 vs. 0.55 in the tributary part). We obtained a better fit for separate localities in the case of biomass-based indicators. Therefore, biomass indicators were used with data separated between dam and tributary, which reflected the longitudinal gradient in nutrient concentration, i.e., scoring class boundary for biomass at the tributary was twice as high as this at the dam. In terms of abundance, one number integrating all localities and depths was used because its split into separate localities was not favoured during the selection of indicators.

Four species-specific indicators fall under the WFD criterion of fish community composition (Tab. 1). Common bream biomass and ruffe abundance increased with TP, and the highest environmental impact was expected in the benthic habitat with higher association of this species. The relative biomass of European perch, especially in the pelagic zone, decreased with $\mathrm{TP}(\rho=-0.57$ in pelagic $v s .-0.02$ in benthic habitat, Tab. S3). A similar trend was observed for the relative biomass of rudd, but the average biomass in all habitats was selected because of its rarity (mean $3.33 \%$ of total BPUE). Three tested indicators evaluating the common carp population had a low correlation with TP $\left(\rho_{\mathrm{TP}} \leq 0.08\right)$ and were excluded. Indicators evaluating the pikeperch and roach populations were correlated with TP (highest $\rho_{\mathrm{TP}}=0.55$ for roach and $\rho_{\mathrm{TP}}=0.75$ for pikeperch, both in the pelagic habitat), but the relationships were driven by outliers in the data and did not allow the setting of proper scoring criteria, so both species were thus excluded.

The occurrence of Salmonidae was scored in the context of reservoir altitude. High occurrence ( $>2 \%$ of total fish biomass) in lowland and middle altitude reservoirs $(<700 \mathrm{~m}$ a s.l) increased the EQR, while low occurrence $(<2 \%$ of total fish biomass) in mountain reservoirs ( $\geq 700 \mathrm{~m}$ a s 1$)$ decreased the EQR. The biomass threshold representing a presumably viable population was based on our observation (Tab. S2) and study of Gassner et al. (2003). None of the guild or measured size structure indicators were selected because their relationship with TP was relatively weak (mean $\rho_{\mathrm{TP}}=-0.18-0.31$ ), and the strongest correlations were difficult to interpret, such as an increasing size or number of phytophilous species with TP. The age structure WFD criterion was evaluated by the presence of $0+$ fish of the six species (Tab. 1).

\subsection{Indicators and index validation}

Spearman correlation coefficients between indicators falling under the WFD criterion of abundance were moderately positive (mean $\pm \mathrm{SE}=0.56 \pm 0.09$, range $0.41-0.71$ ), and those describing community composition ranged from moderately negative to moderately positive (mean $\pm \mathrm{SE}=-0.04 \pm 0.09$, range $-0.64-0.63)$. No redundant indicators with correlations lower than -0.8 or higher than 0.8 were thus identified.

Based on the EQR values, the sampled reservoirs covered the gradient from 'Good' to 'Bad' EP. Most reservoirs fell under the 'Poor' status category (47\%). Correlation of EQRs with TP concentration was relatively tight (coefficient of determination $R^{2}=0.68$, Fig. 2). EQR values in reservoirs with multiple surveys were almost always consistent between years

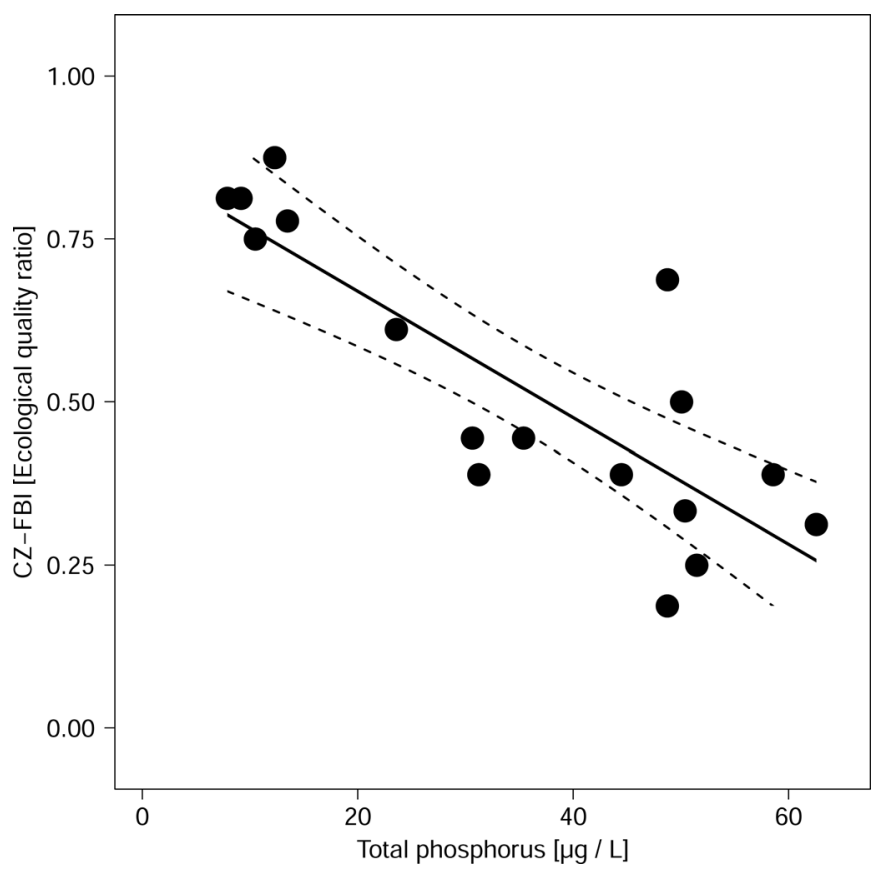

Fig. 2. Relationship between the Czech fish-based index (CZ-FBI) and total phosphorus concentration (TP) in 17 reservoirs. Dashed lines= $95 \%$ confidence interval. Regression line ( \pm SE parameter values): $\mathrm{CZ}$ $=(0.863 \pm 0.067)-(0.010 \pm 0.002) \mathrm{TP}, R^{2}=0.68, p<0.001$.

(Fig. 3). The coefficient of variation for reservoir-specific EQR interannual variability ranged from 0.048 (Zlutice Reservoir) to 0.327 (Vir Reservoir), and the average across all data was 0.147. All but two reservoirs (Nyrsko and Vir reservoirs) remained in the same EP classification over the dataset.

\subsection{Sensitivity analysis}

Fish abundance and biomass were the most sensitive indicators (Tab. 2). Perturbing the observed values by $\pm 10 \%$ changed the total EQR on average by $21 \%$ (i.e., an absolute change of 0.06 in EQR values). Larger perturbations of $\pm 25 \%$ increased the average change in EQR values to $46 \%$. The relative biomass of common bream and the relative abundance of ruffe were most sensitive to perturbations, while the relative biomass of European perch, rudd and Salmonidae were the least sensitive indicators. The main difference between sensitive and insensitive indicators was the presence of zero values in the data, as more zeroes in the dataset decreased the sensitivity (Tab. 2).

\subsection{Comparison of CZ-FBI to CWE-FBI}

CZ-FBI correlated highly with CWE-FBI $\left(R^{2}=0.85\right)$, although the former yielded a more strict assessment of EP. EQR values based on CZ-FBI were, on average, lower by 0.11 compared to CWE-FBI, i.e., most points are below the 1:1 reference line in Figure 4.

\section{Discussion}

The WFD requires the assessment of the ecological quality of all water bodies but does not provide strict guidance for the 


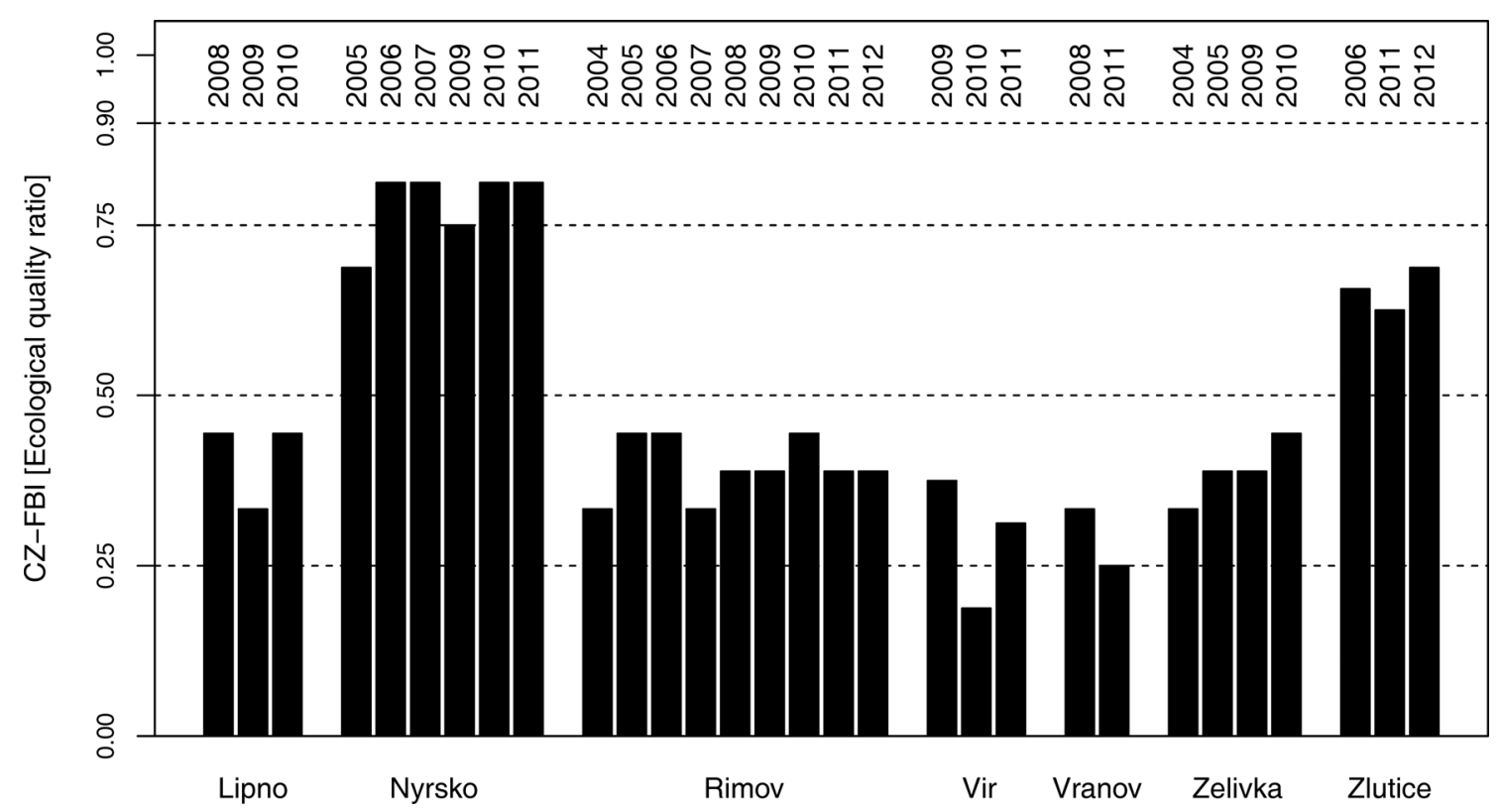

Fig. 3. Long-term stability of the Czech fish based index (CZ-FBI) in seven repeatedly sampled reservoirs. Vertical lines represent classes of ecological potential. Years above columns refer to year of sampling.

Table 2. Results of the sensitivity test. Zeroes = percentage of zero values in the dataset; response=percentage of EQR change between ecological classes to a given change in the indicator.

\begin{tabular}{lcll}
\hline Indicators & Zeroes & Response to $\pm 10 \%$ change & Response to $\pm 25 \%$ change \\
\hline Total fish biomass in dam part & 0 & 17 & 37 \\
Total fish biomass in tributary part & 0 & 20 & 34 \\
Total fish abundance & 0 & 27 & 68 \\
Relative biomass of common bream & 29 & 12 & 27 \\
Relative abundance of ruffe & 24 & 5 & 24 \\
Relative biomass of European perch & 2 & 2 & 12 \\
Relative biomass of rudd & 27 & 2 & 10 \\
Relative biomass of Salmonidae & 71 & 5 & 10 \\
Presence of 0+ fish (6 common species) & 0 & 6 & 9 \\
\hline
\end{tabular}

development of the assessment methodology. Development of these methodologies is challenging, especially in data-poor conditions. Despite this issue, newly developed indices that focus on a particular type of water body, such as the CZ-FBI developed here for Czech reservoirs, can provide valuable insight into the ecological potential of the given water bodies and address specific questions. The CZ-FBI clearly defines fish indicators, enabling fast classification of ecological potential and, when required, providing guidance for restoration actions and fishery management. The methodological steps used to develop the new index are transferable to other regions in similar reservoirs located in comparable environment and sharing the same species. This study should therefore be useful beyond the neighbouring countries that can directly apply the CZ-FBI approach.

The CZ-FBI is based on well-defined indicators that correlate with eutrophication (expressed as TP concentration) and cover all criteria required by the WFD, i.e., the evaluation of abundance, fish community composition and age structure.
CZ-FBI includes nine fish indicators, which is similar to the European average of eight per index (Birk et al., 2012). The indicators include measures of total fish abundance and biomass, fish composition at a species and family level, and a proxy for reproductive success. The selected species are widely distributed and constitute a significant part of fish communities across Europe (Kottelat and Freyhof, 2007). They share some functional characteristics, but separate ecological classification of each species can provide results that are directly interpretable for fishery managers. Moreover, the CZ-FBI reflects the inherent spatial heterogeneity of reservoirs in terms of fish distribution by covering longitudinal and depth gradients in benthic and pelagic habitats, but this feature does not compromise its utility. This combination of indicators should provide an index that is comparable to those developed for natural water bodies, such as lakes or rivers (Birk et al., 2012).

Not surprisingly, the differences in data covering one country (CZ-FBI) and a continent (CWE-FBI) resulted in 


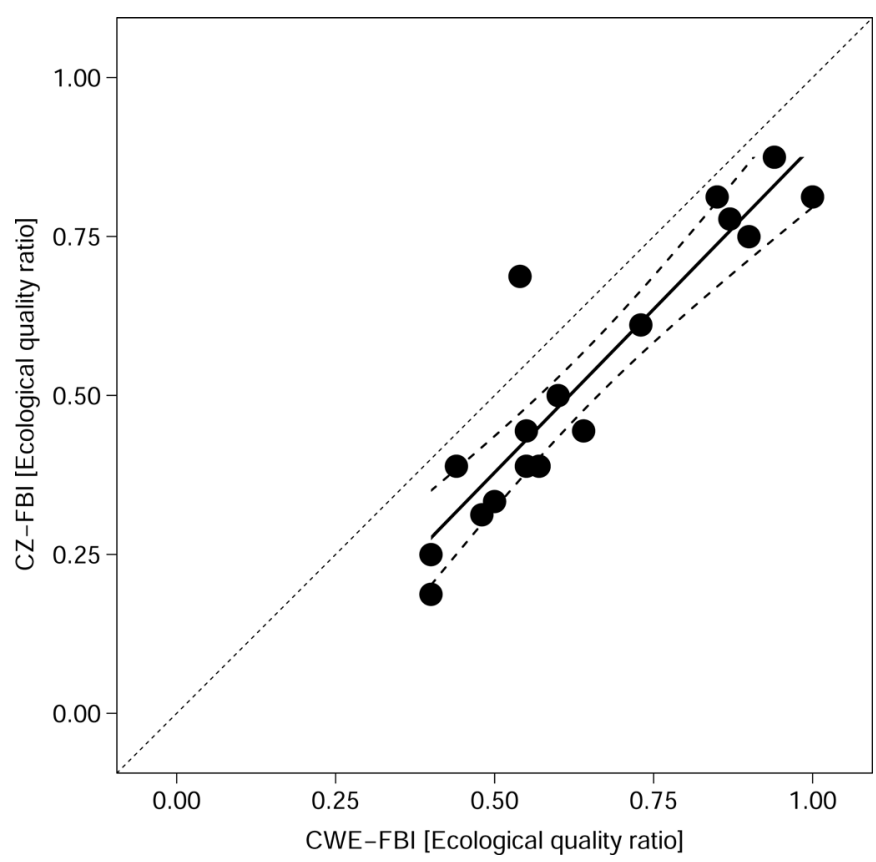

Fig. 4. Relationship between ecological quality ratios evaluated by the Czech fish based index (CZ-FBI) and the common index for Central and Western Europe (CWE-FBI). Thick= mean relationship; dashed lines $=95 \%$ confidence interval; dotted line $=1: 1$ relationship . Regression line (mean \pm SE parameter values): $\mathrm{CZ}-\mathrm{FBI}=(-0.135 \pm$ $0.075)+(1.027 \pm 0.112)$ CWE-FBI, $R^{2}=0.85, p<0.001$.

different indicator selection. The CZ-FBI uses mainly single species indicators, while CWE-FBI is based on functional guilds. In terms of WFD criteria, CWE-FBI does not cover age structure. This limitation is common across national indices (Gassner et al., 2005, Søndergaard et al., 2005), and in indices covering larger spatial scales (Pont et al., 2007; Argillier et al., 2013). Direct assessment of age structure is difficult, expensive and time consuming. Indirect assessment (e.g., based on size distribution) is therefore more common but was found to be insensitive to anthropogenic pressures (Kelly et al., 2012; Emmrich et al., 2014). Therefore, age-structure in the CZ-FBI was assessed indirectly by presence or absence of $0+$ fish, which is easy to determine from size distribution and provides a reliable proxy for the presence of young fish beyond current recruits.

Indicators fish biomass in pelagic habitat of dam and tributary parts and abundance in benthic habitat in whole reservoir are related with the WFD criteria fish abundance and they were positively correlate with TP concentration. Such result is with concordance to previous studies of Belpaire et al. (2000), Søndergaard et al. (2005), Launois et al.(2011a, b) and Kelly et al. (2012). The fish biomass indicators were used in both CWE-FBI and CZ-FBI. In case of CWE-FBI, the biomass indicator is an integral value for the whole benthic habitat while we calculated biomass indicators for pelagic habitat separately in dam and tributary part. Advantage of this approach is taking into account longitudinal productivity gradient in reservoir ecosystems (Blabolil et al., 2017). In typical canyon-shaped reservoir (dominant type in the Czech Republic) productivity decrease gradually with distance from a main tributary (Vašek et al., 2016). Indicators calculation for dam and tributary parts apart enable to assess whether these crucial indicators are out of range of good class boundary in whole reservoir or only in a particular part. Similarly as fish biomass, the increase of fish abundance, mainly planktivorous species, with productivity is related with higher food availability (Jeppesen et al., 2000). In case of CZ-FBI, the abundance in whole benthic habitat had the best fit with the TP concentration and was included to the index.

The populations of common bream and ruffe increase with productivity (Jeppesen et al., 2000; Mehner et al., 2005) and their densities (relative biomass for bream and relative abundance for ruffe in benthic habitats) positively correlated with TP concentration. Both are benthic species classifies in guilds phyto-lithophilic, omnivorous and tolerant (Blabolil et al., 2016). They are adapted to conditions of lower river parts with higher trophy and turbidity and therefore, increase of their densities are good indicators for increase of trophy. So far, broader utilization of common bream as indicator was not used because common bream as a large body species is often underestimated in standard 12 mesh sizes gillnets (CEN, 2005). However, gillnets used for our study were extended by four large mesh sizes to increase the estimate reliability of large bodied species (Šmejkal et al., 2015).

The relative contribution of European perch and rudd in fish communities decreases with productivity (Jeppesen et al., 2000). Proportion of European perch in biomass decreased significantly with TP concentration and therefore, it was used as positive indicators in CZ-FBI. European perch is visually oriented predator and it is outcompete by cyprinids in eutrophic conditions. Relationship between rudd biomass and TP concentration was not as clear as for other indicators. The reason is that rudd is indicator not only for eutrophication but also for other stressors as hydromorphological alteration and littoral degradation. Eutrophication and water level fluctuation in reservoirs often limit macrophyte development. Rudd is an obligatory phytophilous spawner and its density largely reflects macrophyte quantity in a waterbody. Therefore, higher rudd proportions indicates ecologically more valuable conditions (less eutrophic with presence of submerged macrophytes) and rudd was selected indicator to CZ-FBI even without clear relationship with TP.

Similarly as for rudd, the presence of Salmonidae was considered as indicator for good quality conditions even when correlation with TP was not satisfactory. In case of assessed reservoirs, Salmonidae occurred naturally in all rivers before their damming and they were even stocked to several reservoirs (particularly whitefish). Under favourable conditions Salmonidae should be present in these reservoirs and establish viable populations. Salmonidae is associated with high quality, cold, oxygen-rich waters which can be found only in hypolimnion during summer warm period (Gassner et al., 2003, 2005; Carol et al., 2006). Eutrophication usually caused oxygen depletion in lower parts of water column and unfavourable conditions for Salmonidae, therefore, absence of Salmonidae indicates negative alteration of water column caused by eutrophication.

The assessment of natural reproduction is ecologically important to determine sustainability of fish populations. Most of fish species are sensitive to environment during early stages. In conditions of high eutrophication, the parameters such as oxygen concentration and $\mathrm{pH}$ fluctuate during day and night 
period, the other eutrophication impact is increase of sedimentation resulting in spawning habitat degradation and reduction of macrophytes via transparency decrease limiting shelters for young fish (Wetzel, 2001). Despite the theory, in this dataset presence of $0+$ fish increase with TP concentration. The main reason is TP concentration range reaching maximum of eutrophic conditions without strong negative effect such as fish kills (Jeppesen et al., 2000). The selected six species are mainly tolerant species with broad distribution, the $0+$ fish can tolerate eutrophic conditions in reservoirs or find a suitable refuge, e.g. tributaries. Moreover, the smallest diversity of $0+$ fish was observed in the reservoirs with lowest trophy located on small streams in higher altitudes. This result is not surprising as species diversity is naturally low in these reservoirs. To correct this natural phenomena we set the ecological class boundaries relatively softly. Moreover, we add an exception not to use this indicator in case of presence of high European perch biomass because this species can strongly reduce quantity of $0+$ fish in a reservoir.

Beside the indicators, the development of the CZ-FBI was based on pairwise correlations with TP concentration, supported by expert judgement and literature review, while the CWE-FBI relies on hindcasting procedures. Such advanced modelling may reveal causal relationships for sufficiently large datasets (ter Braak and Verdonschot, 1995) but is usually not applicable to relatively small datasets such as those underlying the CZ-FBI. Instead, simple methods can identify clear patterns in the dataset (Mouton et al., 2010). Expert judgement was also involved in the development of CZ-FBI; this subjective approach is appropriate when undisturbed reference conditions do not exist and a limited dataset is available (Moss, 2008). Despite the different underlying approaches, both indices lead to very similar results. This confirms the ability of either assessment to classify the EP of reservoirs on a gradient of anthropogenic pressure. The classification of the same reservoirs based on CZ-FBI was stricter than that of CWE-FBI, due to a larger gradient of pressures used in the development of CWE-FBI or because of the overall better state of the Czech reservoirs (Blabolil et al., 2016). The very high value of CZ-FBI compared to assessment by CWE-FBI for one reservoir (Lucina in Fig. 4) is caused by low proportion of fish species categorised as negative indicators and vice versa for positive indicators (e.g., presence of whitefish in hypolimnion). Therefore, the weight of the species-specific indices is higher in CZ-FBI than aggregated BPUE and NPUE in CWE-FBI. This example particular demonstrate the advantage of a local index.

Both indices were validated using several approaches. Tight correlations of EQR with TP concentration suggest that poor classified reservoirs have seriously affected communities requiring mitigation measures. Moreover, EQR showed high interannual stability in reservoirs across long time series, especially Nyrsko and Rimov, although the variation occasionally led to changes in the EP classification, when the mean EQR was close to a boundary between two categories. The management practice and environmental variables in the time series did not change and therefore the assessment stability confirmed quality of the index.

The development of biological assessment methods is often hampered by limited data availability. The newly developed CZ-FBI could be further improved by using more comprehensive data. The data used in this study were collected using the robust gillnet sampling methodology that is commonly used throughout the European continent (Argillier et al., 2013). It has the well-recognized drawbacks of being size- and species-selective and is unsuitable for some specific habitats such as very shallow water near the shore, which leads to the underestimation of some species or size categories. Therefore, this routine sampling could be extended by use of other methods such as electrofishing in the littoral, purse seining, or hydroacoustic abundance and biomass estimates. Such extensions, despite being more costly and time-consuming, would enable the inclusion of new data-rich indicators. Other improvements to the CZ-FBI could encompass new indicators unveiling other pressures, including acidification, pollution by oil products and drug metabolites, changes in hydro-morphological characteristics such as shoreline modification, lake use (including recreation and water use), habitat reduction, water level fluctuation, and connectivity interruption. Deep analysis of primary purposes for each reservoir should be done to evaluate the best management practice for ecological function. This will be highly challenging, as reservoirs were usually build to serve multiple function. In this dataset only four smallest reservoirs have one primary purpose (drinking water supply). The others have up to four primary and up to seven secondary purposes, e.g., energy production having the main contribution on water level fluctuation is listed as second to seventh purpose. Additional biotic pressures may include selective removal and stocking of native and alien species that interact with the original fish community.

In summary, the newly developed CZ-FBI provides a simple methodology to assess the EP of reservoirs in the Czech Republic. It is applicable in neighbouring countries that can use it directly, and the approach is amenable to modifications to reflect fish communities elsewhere. The index can be further used to identify ecosystems' health and guide future restoration actions to minimize negative anthropogenic effects.

\section{Supplementary Material}

\section{Supplementary Tables.}

The Supplementary Material is available at https://www.kmaejournal.org/10.1051/kmae/2017043/olm.

Acknowledgements. We thank many people and agencies who provided data, especially FishEcU members (www.fishecu.cz) and river authorities in the Czech Republic. We also thank M. Morris for English language corrections. This study was supported by the project CEKOPOT (CZ.1.07/2.3.00/ 20.0204), co-financed by the European Social Fund and the state budget of the Czech Republic; by funds from the Czech Science Foundation (15-01625S); the University of South Bohemia (145/2013/P); and SoWa Research Infrastructure funded by MEYS CZ grant LM2015075, programme "Projects of Large Infrastructure for Research, Development, and Innovations". D. Ricard was supported by the Postdok_BIOGLOBE project (CZ.1.07/2.3.00/30.0032) co-financed by the European Social Fund and the state budget of the Czech Republic. 


\section{References}

Agostinho AA, Gomes LC, Santos NCL, Ortega JCG, Pelicice FM. 2016. Fish assemblages in neotropical reservoirs: colonization patterns, impacts and management. Fish Res 173: 26-36.

Argillier C, Caussé S, Gevrey M, Pédron S, De Bortoli J, Brucet S, Emmrich M, Jeppesen E, Lauridsen T, Mehner T, Olin M, Rask M, Volta P, Winfield I, Kelly F, Krause T, Palm A, Holmgren K. 2013. Development of a fish-based index to assess the eutrophication status of European lakes. Hydrobiologia 704: 193-211.

Baker EA, Wehrly KE, Seelbach PW, Wang L, Wiley MJ, Simon T. 2005. A multimetric assessment of stream condition in the northern lakes and forests ecoregion using spatially explicit statistical modeling and regional normalization. Trans Am Fish Soc 13: $697-710$

Belpaire C, Smolders R, Auweele IV, Ercken D, Breine J, Thuyne G Van, Ollevier F. 2000. An index of biotic integrity characterizing fish populations and the ecological quality of flandrian water bodies. Hydrobiologia 434: 17-33.

Birk S, Bonne W, Borja A, Brucet S, Courrat A, Poikane S, Solimini A, van de Bund W, Zampoukas N, Hering D. 2012. Three hundred ways to assess Europe's surface waters: an almost complete overview of biological methods to implement the Water Framework Directive. Ecol Indic 18: 31-41.

Blabolil P, Logez M, Ricard D, Prchalová M, Říha M, Sagouis A, Peterka J, Kubečka J, Argillier C. 2016. An assessment of the ecological potential of Central and Western European reservoirs based on fish communities. Fish Res 173: 80-87.

Blabolil P, Boukal DS, Ricard D, Kubečka J, Ríha M, Vašek M, Prchalová M, Čech M, Frouzová J, Jůza T, Muška M, Tušer M, Draštík V, Šmejkal M, Vejř́k L, Peterka J. 2017. Optimal gillnet sampling design for the estimation of fish community indicators in heterogeneous freshwater ecosystems. Ecol Indic 77: 368-376.

Boukal DS, Jankovský M, Kubečka J, Heino M. 2012. Stock-catch analysis of carp recreational fisheries in Czech reservoirs: insights into fish survival, water body productivity and impact of extreme events. Fish Res 119-120: 23-32.

Carol J, Benejam L, Alcaraz C, Vila-Gispert A, Zamora L, Navarro E, Armengol J, Garcia-Berthou E. 2006. The effects of limnological features on fish assemblages of 14 Spanish reservoirs. Ecol Freshwater Fish 15: 66-77.

Carpenter SR, Kitchell JF, Hodgson JR. 1985. Cascading trophic interactions and lake productivity. BioSci 35: 634-639.

CEN. 2005. Water Quality - Sampling of fish with multimesh gillnets. European Committee for Standardization, EN 14757, Brussels.

CFU. 2017. Czech Fishing Union - Statistics catches. www.rybsvaz. cz $(9 / 2017)$.

EC. 2000. Directive 2000/60/EC of the European Parliament and the Council of 23rd October 2000 establishing a framework for community action in the field of water policy. Official Journal of the European Communities L327: 1-72.

Emmrich M, Pédron S, Brucet S, Winfield IJ, Jeppesen E, Volta P, Argillier C, Lauridsen TL, Holmgren K, Hesthagen T, Mehner T. 2014. Geographical patterns in the body-size structure of European lake fish assemblages along abiotic and biotic gradients. $J$ Biogeogr 14: 2221-2233.

Froese R, Pauly D. 2016. FishBase. World Wide Web electronic publication. www.fishbase.org. (10/2016).

Gassner H, Tischler G, Wanzenböck J. 2003. Ecological integrity assessment of lakes using fish communities - suggestions of new metrics developed in two Austrian prealpine lakes. Int Rev Hydrobiol 88: 635-652.
Gassner H, Wanzenböck J, Zick D, Tischler G, PammingerLahnsteiner B. 2005. Development of a fish based lake typology for natural Austrian lakes $>50$ ha based on the reconstructed historical fish communities. Int Rev Hydrobiol 90: 422-432.

Hutchinson GE. 1957. Concludig remarks. Cold Spring Harbor Symposia on Quantitative Biology 22: 415-427.

Illies J. 1978. Limnofauna Europaea. A checklist of the animals inhabiting european inland waters, with account of their distribution and ecology. Stuttgart and Swets \& Zeitlinger: Amsterdam, $532 \mathrm{p}$.

Irz P, Odion M, Argillier C, Pont D. 2006. Comparison between the fish communities of lakes, reservoirs and rivers: can natural systems help define the ecological potential of reservoirs? Aquat Sci 68: 109-116.

Jeppesen E, Jensen JP, Søndergaard M, Lauridsen T, Landkildehus F. 2000. Trophic structure, species richness and biodiversity in Danish lakes: changes along a phosphorus gradient. Freshwater Biol 45: 201-218.

Jeppesen E, Søndergaard M, Jensen JP, Havens KE, Anneville O, Carvalho L, Coveney MF, Deneke R, Dokulil MT, Foy B, Gerdeaux D, Hampton SE, Hilt S, Kangur K, Kohler J, Lammens EHHR, Lauridsen TL, Manca M, Miracle MR, Moss B, Noges P, Persson G, Phillips G, Portielje R, Schelske CL, Straile D, Tatrai I, Willen E, Winder M. 2005. Lake responses to reduced nutrient loading - an analysis of contemporary long-term data from 35 case studies. Freshwater Biol 50: 1747-1771.

Jůza T, Vašek M, Kratochvíl M, Blabolil P, Čech M, Draštík V, Frouzová J, Muška M, Peterka J, Prchalová M, Říha M, Tušer M, Kubečka J. 2014. Chaos and stability of age- 0 fish assemblages in a temperate deep reservoir: unpredictable success and stable habitat use. Hydrobiologia 724: 217-234.

Karr JR, Fausch KD, Angermeier PL, Yant PR, Schlosser IJ. 1986. Assessing biological integrity in running waters: a method and its rationale. Illinois Natural History Survey: Champaign, 28 p.

Kelly FL, Harrison AJ, Allen M, Connor L, Rosell R. 2012. Development and application of an ecological classification tool for fish in lakes in Ireland. Ecol Indic 18: 608-619.

Kottelat M., Freyhof J. 2007. Handbook of European freshwater fishes. Kottelat: Copeia, 646 p.

Krolová M, Č́žzová H, Hejzlar J, Poláková S. 2013. Response of littoral macrophytes to water level fluctuations in a storage reservoir. Knowl Manag Aquat Ecosyst 408: 1-21.

Kubečka J. 1993. Succession of fish communities in reservoirs of Central and Eastern Europe. In: Straškraba M, Tundisi JG, Duncan A (eds). In comparative reservoir limnology and water quality management, developments in hydrobiology. Springer Netherlands: Dordrecht, 153-168.

Kubečka J, Hohausová E, Matěna J, Peterka J, Amarasinghe US, Bonar SA, Hateley J, Hickley P, Suuronen P, Tereschenko V, Welcomme R, Winfield IJ. 2009. The true picture of a lake or reservoir fish stock: A review of needs and progress. Fish Res 96: $1-5$.

Lammens E, van Luijn F, Wessels Y, Bouwhuis H, Noordhuis R, Portielje R, van der Molen D. 2008. Towards ecological goals for the heavily modified lakes in the IJsselmeer area, the Netherlands. Hydrobiologia 599: 239-247.

Launois L, Veslot J, Irz P, Argillier C. 2011a. Development of a fishbased index (FBI) of biotic integrity for French lakes using the hindcasting approach. Ecol Indic 11: 1572-1583.

Launois L, Veslot J, Irz P, Argillier C. 2011b. Selecting fish-based metrics responding to human pressures in French natural lakes and reservoirs: towards the development of a fish-based index (FBI) for French lakes. Ecol Freshwater Fish 20: 120-132. 
McCluney KE, LeRoy Poff N, Palmer MA, Thorp JH, Poole GC, Williams BS, Williams MR, Baron JS. 2014. Riverine macrosystems ecology: sensitivity, resistance, and resilience of whole river basins with human alterations. Front Ecol Environ 12: 48-58.

Mehner T, Diekmann M, Brämick U, Lemcke R. 2005. Composition of fish communities in German lakes as related to lake morphology, trophic state, shore structure and human-use intensity. Freshwater Biol 50: 70-85.

Mouton AM, Dedecker AP, Lek S, Goethals PLM. 2010. Selecting variables for habitat suitability of Asellus (Crustacea, Isopoda) by applying input variable contribution methods to artificial neural network models. Environ Model Assess 15: 65-79.

Poikane S, Zampoukas N, Borja A, Davies SP, van de Bund W, Birk S. 2014. Intercalibration of aquatic ecological assessment methods in the European Union: Lessons learned and way forward. Environ Sci Policy 44: 237-246.

Pont D, Hugueny B, Rogers C. 2007. Development of a fish-based index for the assessment of river health in Europe: the European Fish Index. Fish Manag Ecol 14: 427-439.

Prchalová M, Kubečka J, Ř́ha M, Mrkvička T, Vašek M, Jůza T, Kratochvíl M, Peterka J, Draštík V, Kř́žžek J. 2009. Size selectivity of standardized multimesh gillnets in sampling coarse European species. Fish Res 96: 51-57.

Prchalová M, Mrkvička T, Kubečka J, Peterka J, Čech M, Muška M, Kratochvíl M, Vašek M. 2010. Fish activity as determined by gillnet catch: a comparison of two reservoirs of different turbidity. Fish Res 102: 291-296.

R Core Team. 2015. R: A language and environment for statistical computing. R Foundation for Statistical Computing, Vienna, Austria.

Ritterbusch D. 2011. Proposal of an alternative option to assure that national good/moderate class boundaries correspond to comparable levels of ecosystem alteration. Draft proposal discussed at meeting on November 18 2011. In: The Institute of Inland Fisheries: Potsdam-Sacr, $35 \mathrm{p}$.

Scheffer M, Carpenter S, Foley JA. Folke C. Walker B. 2001. Catastrophic shifts in ecosystems. Nature 413: 591-596.
Schmidt-Kloiber A, Hering D. 2015. www.freshwaterecology.info an online tool that unifies, standardises and codifies more than 20,000 European freshwater organisms and their ecological preferences. Ecol Indic 53: 271-282.

Segurado P, Caiola N, Pont D, Oliveira JM, Delaigue O, Ferreira M-T. 2014. Comparability of fish-based ecological quality assessments for geographically distinct Iberian regions. Sci Total Environ 476477: 785-794.

Šmejkal M, Ricard D, Prchalová M, Ř́ha M, Muška M, Blabolil P, Čech M, Vašek M, Jůza T, Herreras AM, Encinad L, Peterka J, Kubečka J. 2015. Biomass and abundance biases in European standard gillnet sampling. PLOS ONE 10: 1-15.

Søndergaard M, Jeppesen E, Peder Jensen J, Lildal Amsinck S. 2005. Water Framework Directive: ecological classification of Danish lakes. J Appl Ecol 42: 616-629.

Stefanidis K, Papastergiadou E. 2013. Effects of a long term water level reduction on the ecology and water quality in an eastern mediterranean lake. Knowl Manag Aquat Ecosyst 411: 1-14.

Sutela T, Vehanen T, Rask M. 2011. Assessment of the ecological status of regulated lakes: stressor-specific metrics from littoral fish assemblages. Hydrobiologia 675: 55-64.

Ter Braak CJF, Verdonschot PFM. 1995. Canonical correspondence analysis and related multivariate methods in aquatic ecology. Aquat Sci 57: 255-289.

Thornton KW, Kimmel BL, Payne FE. 1990. Reservoir limnology: ecological perspectives. John Wiley \& Sons: New York, 307 p.

Vašek M, Prchalová M, Říha M, Blabolil P, Čech M, Draštík V, Frouzová J, Jůza T, Kratochvíl M, Muška M, Peterka J, Sajdlová Z, Šmejkal M, Tušer M, Vejř́ík L, Znachor P, Mrkvička T, Sed’a J, Kubečka J. 2016. Fish community response to the longitudinal environmental gradient in Czech deep-valley reservoirs: implications for ecological monitoring and management. Ecol Indic 63: 219-230.

Vollenweider RA. 1976. Advances in defining critical loading levels for phosphorus in lake eutrophication. Memorie dell' Istituto Italiano di Idrobiologia 33: 53-83.

Wetzel RG. 2001. Limnology: lake and river ecosystems 3rd ed. 37 Academic Press: New York, 1006 p.

Cite this article as: Blabolil P, Ř́ha M, Ricard D, Peterka J, Prchalová M, Vašek M, Čech M, Frouzová J, Jůza T, Muška M, Tušer M, Draštík V, Sajdlová Z, Šmejkal M, Vejř́ík L, Matěna J, Boukal DS, Ritterbusch D, Kubečka J. 2017. A simple fish-based approach to assess the ecological quality of freshwater reservoirs in Central Europe. Knowl. Manag. Aquat. Ecosyst., 418, 53. 